\title{
Prognosis of recurrent non-small cell lung cancer following complete resection
}

\author{
HIDEFUMI SASAKI, AYUMI SUZUKI, TSUTOMU TATEMATSU, MASAYUKI SHITARA, YU HIKOSAKA, \\ KATSUHIRO OKUDA, SATORU MORIYAMA, MOTOKI YANO and YOSHITAKA FUJII \\ Department of Oncology, Immunology and Surgery, \\ Nagoya City University Graduate School of Medical Sciences, Nagoya, Aichi 467-8601, Japan
}

Received July 12, 2013; Accepted January 9, 2014

DOI: $10.3892 / \mathrm{ol} .2014 .1861$

\begin{abstract}
Prognosis following recurrence subsequent to complete resection of non-small-cell lung cancer (NSCLC) is considered a multifactorial process dependent on clinicopathological, biological and treatment characteristics. Gefitinib was approved for lung cancer treatment in Japan in 2002. The aim of the current study was to quantify the prognostic effects of these characteristics on post-recurrence prognosis. In total, 127 NSCLC patients were analyzed who underwent complete resection and subsequently had recurrent cancer. The correlation between characteristics of the initial and recurrent disease with post-recurrence prognosis was investigated. The factors clearly associated with post-recurrence prognosis using Cox proportional hazards models were age at recurrence (those $<65$ years of age typically had better prognoses) and interval between initial resection and recurrence (intervals of $<1$ year accompanied a worse prognosis). Epidermal growth factor receptor (EGFR) mutant patients treated with EGFR tyrosine kinase inhibitors (TKIs), exhibited the longest median survival following recurrence (37.4 months) in the sample. Treatment, particularly EGFR TKIs for recurrent NSCLC, was observed to significantly prolong survival. The results of the study highlight that various treatment modalities according to the clinical background of the patient should be considered in patients with postoperative recurrent NSCLC.
\end{abstract}

\section{Introduction}

Lung cancer is the leading cause of cancer-associated mortality worldwide. For patients with early-stage (stage I and II) non-small cell lung cancer (NSCLC) and for appropriately selected patients with locally advanced disease (stage IIIA), complete surgical resection is the optimal treatment. Although

Correspondence to: Dr Hidefumi Sasaki, Department of Oncology, Immunology and Surgery, Nagoya City University Graduate School of Medical Sciences, 1 Kawasumi, Nagoya, Aichi 467-8601, Japan E-mail: hisasaki@med.nagoya-cu.ac.jp

Key words: EGFR, recurrent, prognosis, tyrosine kinase inhibitor advancements in early diagnosis and treatment have been made in the hope of improving survival, recurrence remains a major problem. Reported recurrence rates following complete surgical resection range between 30 and $75 \%$ (1-6) [ 15\% for pathological stage (p-stage) I cases $(7,8)]$. The majority of recurrent tumors are distant and $>80 \%$ of recurrences occur within the first 2 years after resection.

Several previous studies have evaluated the prognostic factors associated with survival following recurrence of NSCLC. Chemotherapy and radiation therapy are generally accepted treatment options for recurrent NSCLC. Encouraging new treatments [including epidermal growth factor receptor-tyrosine kinase inhibitors (EGFR-TKIs), anaplastic lymphoma kinase inhibitors, pemetrexed and bevacizumab for adenocarcinomas] have benefited specific patients with advanced or recurrent NSCLC (9-15). Identification of activating mutations of EGFR is one of the most important developments in the field of NSCLC. EGFR mutations are present predominantly in females, in never-smokers and in Asian individuals, and are sensitive to EGFR-targeted therapy, including gefitinib (16-18). The response rate to gefitinib is almost $75 \%$ in patients with tumors harboring EGFR mutations in Asian clinical trials $(9-11,17,18)$. These advances in post-recurrence therapy may improve overall survival among patients who undergo surgery. The present study investigated the clinicopathological factors influencing post-recurrence survival and the effect of post-recurrence therapy on Japanese NSCLC since 2002.

\section{Patients and methods}

Patients. The study group included 637 patients with NSCLC: 435 were diagnosed as having adenocarcinomas, 147 had squamous cell carcinomas, 20 had adenosquamous carcinomas and 10 had large-cell carcinomas. All had undergone complete resection at the Department of Surgery, Nagoya City University Hospital (Nagoya, Japan) between 2002 and 2012. Patients who succumbed to disease without identifiable recurrence were excluded from the study. The lung tumors were classified according to the general rules for clinical and pathological diagnosis of lung cancer in Japan (19).

The clinical and pathological characteristics of the 637 lung cancer patients were as follows: 435 cases at stage I, 93 at 
Table I. Clinicopathological data of 127 lung cancer patients.

\begin{tabular}{|c|c|c|c|c|}
\hline \multirow[b]{3}{*}{ Factors } & \multicolumn{4}{|c|}{ Prognostic analysis } \\
\hline & \multicolumn{3}{|c|}{ Univariate } & \multirow{2}{*}{$\frac{\text { Multivariate }}{\text { HR (P-value) }}$} \\
\hline & Patients, $\mathrm{n}$ & MST, months & P-value & \\
\hline Age, years & & & 0.0060 & $2.299(0.0015)$ \\
\hline$<65$ & 41 & 34.2 & & \\
\hline$\geq 65$ & 86 & 23.2 & & \\
\hline Smoking history & & & 0.0026 & $1.378(0.4548)$ \\
\hline Non-smoker & 81 & 22.2 & & \\
\hline Smoker & 46 & 34.0 & & \\
\hline Pathological subtypes & & & 0.0002 & $1.541(0.0752)$ \\
\hline Adenocarcinoma & 86 & 31.6 & & \\
\hline Non-adenocarcinoma & 41 & 17.9 & & \\
\hline Gender & & & 0.0024 & $1.201(0.6771)$ \\
\hline Male & 83 & 22.3 & & \\
\hline Female & 44 & 34.5 & & \\
\hline Recurrence interval, years & & & 0.0016 & $2.119(0.0027)$ \\
\hline$<1$ & 70 & 21.4 & & \\
\hline$>1$ & 57 & 34.1 & & \\
\hline Brain metastasis & & & 0.2596 & \\
\hline Yes & 18 & 14.5 & & \\
\hline No & 109 & 27.7 & & \\
\hline Bone metastasis & & & 0.4111 & \\
\hline Yes & 28 & 24.1 & & \\
\hline No & 99 & 27.8 & & \\
\hline Liver metastasis & & & 0.0910 & \\
\hline Yes & 4 & 14.5 & & \\
\hline No & 123 & 24.8 & & \\
\hline
\end{tabular}

MST, mean survival time; HR, hazard ratio.

stage II and 109 at stage III. The mean age was $66.8 \pm 9.7$ years (range, 22-87 years). Males accounted for 401 cases and 236 were female. Non-smokers numbered 232. Regarding the mutation of EGFR, the majority of samples from these patients had been analyzed previously $(16,17,20,21)$. EGFR mutations were present in 215 cases and 366 were wild type. The remaining 56 were unknown. This study was approved by the ethics committee of Nagoya City University (Nagoya, Japan). Written informed consent was obtained from the patient.

Post-recurrence survival analysis. Clinical characteristics were retrieved from available clinical records. The following clinicopathological factors were assessed in the post-recurrence analysis: Age, gender, smoking status, pathological stages and histology (adenocarcinoma vs. others). The length of the recurrence-free period was calculated in months between the date of resection and the date of initial recurrence or the date of the last follow-up without recurrence. To calculate the recurrence-free proportion, patients known to have no recurrence at the date of last contact were excluded from this study.
The length of post-recurrence survival was measured between the date of initial recurrence and the date on which the patient succumbed to disease or the date on which the patient was last known to be alive.

Statistical analysis. The overall survival of patients with lung cancers was examined by the Kaplan-Meier methods and differences were examined by the log-rank test. The other clinicopathological characteristics were examined using Student's t-test and $\chi^{2}$ tests as appropriate. Analyses were performed using Statview version 5.0 (Abacus Concepts Inc., Berkeley, CA, USA) or Excel (Microsoft Corporation, Redmond, WA, USA) software and $\mathrm{P}<0.05$ was considered to indicate a statistically significant differences.

\section{Results}

Of the 637 patients, 127 (19.9\%) had recurrent diseases, with a median age of $66.6 \pm 9.3$ years (range, 29-85) at the initial surgery. Median follow-up time for the patients from the 
Table II. Treatment of 127 patients with recurrent lung cancers.

Prognosis

\begin{tabular}{|c|c|c|c|c|}
\hline \multirow[b]{2}{*}{ Treatment } & \multirow[b]{2}{*}{ Samples, $\mathrm{n}$} & & \multirow[b]{2}{*}{ P-value } \\
\hline & & MST, months & Two-year survival, n (\%) & \\
\hline Chemotherapy & & & & 0.0007 \\
\hline Yes & 99 & 29.6 & $37(49.5)$ & \\
\hline No & 28 & 16.3 & $4(23.2)$ & \\
\hline EGFR TKIs & & & & 0.0315 \\
\hline Yes & 39 & 32.8 & $19(55.0)$ & \\
\hline No & 88 & 23.6 & $23(39.2)$ & \\
\hline EGFR mutations & & & & 0.0563 \\
\hline Yes & 40 & 31.6 & $20(50.0)$ & \\
\hline No & 87 & 24.2 & $22(37.8)$ & \\
\hline Radiotherapy & & & & 0.3832 \\
\hline Yes & 82 & 25.4 & $27(42.8)$ & \\
\hline No & 45 & 29.8 & $15(47.8)$ & \\
\hline
\end{tabular}

MST, mean survival time; EGFR, epidermal growth factor receptor; TKI, tyrosine kinase inhibitor.
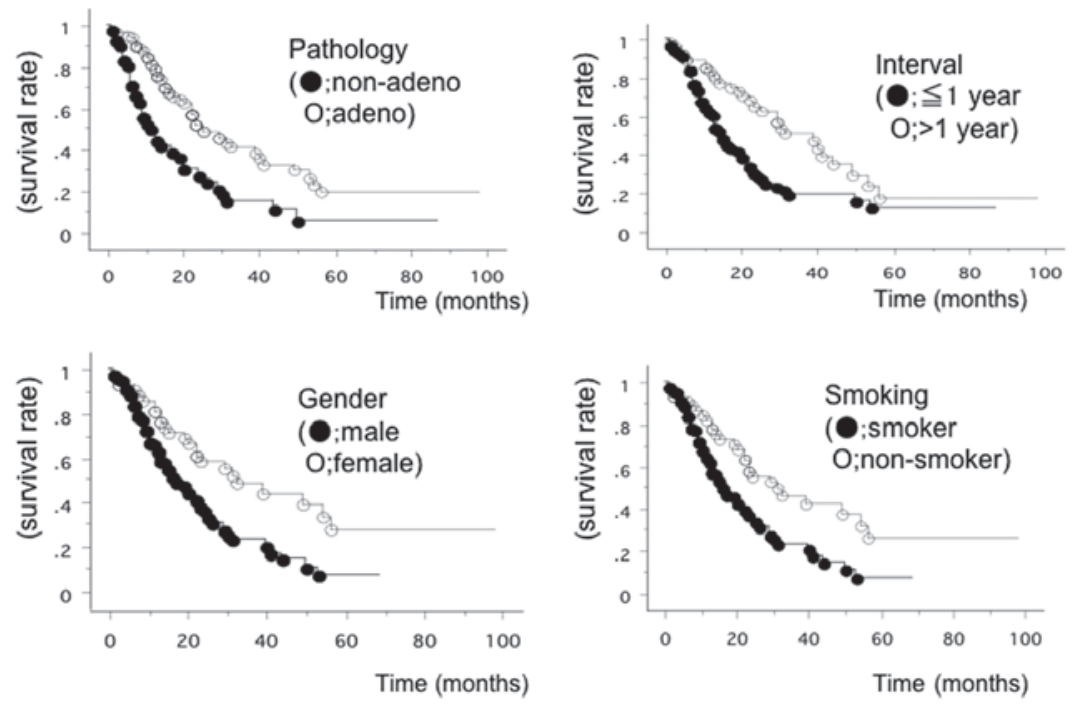

Figure 1. Survival curve for the top 4 prognostic factors.

initial surgery was $38.3 \pm 24.5$ months (range, 4-127 months). Median post-recurrence survival time for these patients was 21.9 \pm 18.4 months (range, 1-98 months). The 1- and 2-year post-recurrence survival proportions were 69.8 and $44.4 \%$, respectively. The recurrence rate was $12.6 \%$ in stage I cases, $37.6 \%$ in stage II and $33.9 \%$ in stage III.

As shown in Table I, univariate and multivariate analyses of recurrence, according to the clinicopathological characteristics of NSCLC patients, were performed. Univariate analysis identified 5 significant risk factors: Male gender $(\mathrm{P}=0.0024)$, a history of smoking $(\mathrm{P}=0.0026)$, non-adenocarcinoma histology $(\mathrm{P}=0.0002)$, an age of $\geq 65$ years old at recurrence $(\mathrm{P}=0.0060)$ and a recurrence interval of $\leq 1$ year $(\mathrm{P}=0.0016)$ (Fig. 1). Multivariate analysis demonstrated that below 65 years old [hazard ratio (HR), 2.299; 95\% confidence interval (CI),

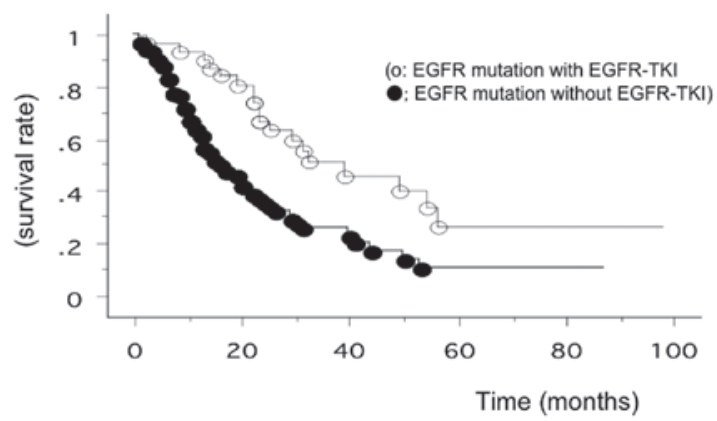

Figure 2. Subgroup analysis revealed that the overall survival of the 29 EGFR-mutant patients treated with EGFR-TKI was 37.4 months (range, 2-98 months after recurrence) and that of other patients was 22.5 months. The median survival of the EGFR-TKI-treated patients with EGFR mutation was the longest in this analysis. EGFR, epidermal growth factor receptor; TKI, tyrosine kinase inhibitor. 
1.374-3.846; $\mathrm{P}=0.0015)$ and a recurrence interval of $<1$ year (HR, 2.119; 95\% CI, 1.296-3.464; $\mathrm{P}=0.027$ ) were statistically significant predictors of shorter survival. EGFR mutation itself was not a prognostic factor.

Initial recurrence sites are shown in Table I and post-recurrent treatment is shown in Table II. Liver metastases were associated with a trend towards poorer prognosis $(\mathrm{P}=0.091)$. However, none of the involved organs, including the bones and brain were significant prognostic factors. Post-recurrence treatment was administered in 114 patients (89.8\%), including chemotherapy for 99 patients and radiotherapy for 82 . Univariate analysis revealed the administration of chemotherapy, but not radiotherapy, to be a prognostic factor. EGFR-TKIs were used in 39 cases and such therapy was revealed to be a marginal prognostic factor by univariate analysis. However, these were not significant prognostic factors according to multivariate analysis. Among the 39 patients treated with EGFR-TKIs, 29 had EGFR mutations. Subgroup analysis placed the overall survival of the 29 EGFR-mutant patients treated with EGFR-TKIs at 37.4 months (range, 2-98 months after recurrence), while that of other patients was 22.5 months. The overall survival of EGFR-TKI-treated patients with EGFR mutation was the longest in the present study (Fig. 2).

\section{Discussion}

In a previous study, Yoshino et al reported that post-recurrence survival of NSCLC patients who underwent complete resection was significantly affected by gender, age at recurrence, p-stage, pulmonary metastasis and recurrence interval (3). In this study, further analysis was conducted with special reference to organ and therapy. Therefore, patients with recurrence were selected between 2002 and 2012 when gefitinib had become a key drug for NSCLC. The results of the present study are similar in part.

The prognostic effect of initial lung cancer stage on survival following recurrent cancer has been investigated. Advanced stages of the initially resected NSCLC have been shown to be associated with increased rates of recurrence and shortened recurrence-free intervals (3,22-24), suggesting the utility of p-stage as a marker of tumor aggressiveness or occult disease at resection. The association of stage with post-recurrence survival has been demonstrated previously, with advanced stages accompanying a 30-90\% increased risk of mortality $(3,22,23)$. Post-operative recurrence is understood as the reappearance of latent cancer cells known as micrometastases. Therefore, the positive correlation between advanced p-stage and high recurrence rate or a short disease-free interval is well understood. However, in the present study p-stage was not a prognostic factor. Appropriately staging and chemotherapy, including EGFR TKI therapy, may overcome the initial pathological stages. However, disease-free interval was a prognostic factor. Walsh et al (23) characterized disease-free interval as an "indirect measure of a patient's tumor biology and aggressiveness". Thus, longer disease-free interval has been reported to be associated with prolonged survival following recurrence in several studies (24-27).

Major advances in NSCLC treatment have resulted from the understanding of the molecular biology of the disease, the development of molecule-targeting agents and the identification of biomarkers for targeted treatment. Since 2002, gefitinib therapy has been approved for the treatment of inoperable or recurrent NSCLC in Japan, hence the focus of the present study on cases subsequent to 2002. EGFR-TKIs have been proven to improve the survival of certain advanced NSCLC patients (28-30), with the overall benefit being determined primarily by the EGFR mutation subgroup $(9-11,16,17,31)$. EGFR-TKIs have also improved endurance and health-related quality of life compared with platinum-based doublet chemotherapy (9-11). EGFR-TKIs are therefore good candidates for first-line post-recurrence treatment in resected adenocarcinoma patients with distant metastases, but only in those with EGFR mutations $(11,28)$.

There are several limitations in the present study. This study is retrospective and bias may exist. Patient selection bias regarding post-recurrence treatment was unavoidable. Curative intent therapy or systematic treatment is difficult to perform in patients with poor performance status and therefore younger patients had better prognoses. In addition, complete follow-up was not available for all eligible patients. One challenge for the future is to create systematic treatment strategies for recurrent NSCLC according to the individual patient's recurrent disease characteristics, including the initial recurrence site, recurrence-free interval and original tumor characteristics.

\section{Acknowledgements}

This study was supported by Grants-in-Aid for Scientific Research, Japan Society for the Promotion of Science (nos. 23659674, 24592097 and 25293303).

\section{References}

1. Martini N, Bains MS, Burt ME, et al: Incidence of local recurrence and second primary tumors in resected stage I lung cancer. J Thorac Cardiovasc Surg 109: 120-129, 1995.

2. al-Kattan K, Sepsas E, Fountain SW and Townsend ER: Disease recurrence after resection for stage I lung cancer. Eur J Cardiothorac Surg 12: 380-384, 1997.

3. Yoshino I, Yohena T, Kitajima M, et al: Survival of non-small cell lung cancer patients with postoperative recurrence at distant organs. Ann Thorac Cardiovasc Surg 7: 204-209, 2001.

4. Martin J, Ginsberg RJ, Venkatraman ES, et al: Long-term results of combined-modality therapy in resectable non-small-cell lung cancer. J Clin Oncol 20: 1989-1995, 2002.

5. Williams BA, Sugimura H, Endo C, et al: Predicting post-recurrence survival among completely resected nonsmall-cell lung cancer patients. Ann Thorac Surg 81: 1021-1027, 2006.

6. Sugimura H, Nichols FC, Yang P, et al: Survival after recurrent non-small-cell lung cancer after complete pulmonary resection. Ann Thorac Surg 83: 409-418, 2007.

7. Hung JJ, Hsu WH, Hsieh CC, et al: Post-recurrence survival in completely resected stage I non-small cell lung cancer with local recurrence. Thorax 64: 192-196, 2009.

8. Shimada Y, Saji H, Yoshida K, et al: Prognostic factors and the significance of treatment after recurrence in completely resected stage I non-small cell lung cancer. Chest 143: 1626-1634, 2013.

9. Maemondo M, Inoue A, Kobayashi K, et al: Gefitinib or chemotherapy for non-small-cell lung cancer with mutated EGFR. N Engl J Med 362: 2380-2388, 2010.

10. Mitsudomi T, Morita S, Yatabe Y, et al: Gefitinib versus cisplatin plus docetaxel in patients with non-small-cell lung cancer harbouring mutations of the epidermal growth factor receptor (WJTOG3405): an open label, randomised phase 3 trial. Lancet Oncol 11: 121-128, 2010.

11. Mok TS, Wu YL, Thongprasert S, et al: Gefitinib or carboplatin-paclitaxel in pulmonary adenocarcinoma. N Engl J Med 361: 947-957, 2009. 
12. Paz-Ares L, de Marinis F, Dediu M, et al: Maintenance therapy with pemetrexed plus best supportive care versus placebo plus best supportive care after induction therapy with pemetrexed plus cisplatin for advanced non-squamous non-small-cell lung cancer (PARAMOUNT): a double-blind, phase 3 , randomised controlled trial. Lancet Oncol 13: 247-255, 2012.

13. Reck M, von Pawel J, Zatloukal P, et al: Overall survival with cisplatin-gemcitabine and bevacizumab or placebo as first-line therapy for nonsquamous non-small-cell lung: results from a randomised phase III trial (AVAiL). Ann Oncol 21: 1804-1809, 2010.

14. Sandler A, Gray R, Perry MC, et al: Paclitaxel-carboplatin alone or with bevacizumab for non-small-cell lung cancer. N Engl J Med 355: 2542-2550, 2006.

15. Scagliotti GV, Parikh P, von Pawel J, et al: Phase III study comparing cisplatin plus gemcitabine with cisplatin plus pemetrexed in chemotherapy-naive patients with advanced-stage non-small-cell lung cancer. J Clin Oncol 26: 3543-3551, 2008.

16. Paez JG, Jänne PA, Lee JC, et al: EGFR mutations in lung cancer: correlation with clinical response to gefitinib therapy. Science 304: 1497-1500, 2004.

17. Sasaki H, Endo K, Mizuno K, et al: EGFR mutation status and prognosis for gefitinib treatment in Japanese lung cancer. Lung Cancer 51: 135-136, 2006.

18. Fukuoka M, Wu YL, Thongprasert S, et al: Biomarker analyses and first overall survival results from a phase III, randomized, open-label, first-line study of gefitinib versus carboplatin/paclitaxel in clinically selected patients with advanced non-small-cell lung cancer in Asia (IPASS). J Clin Oncol 29: 2866-2874, 2011.

19. The Japan Lung Cancer Society: The General Rule for Clinical and Pathological Record of Lung Cancer. 7th edition. Kanehara Shuppan, Tokyo, Japan, pp1-234, 2010.

20. Sasaki H, Endo K, Konishi A, et al: EGFR mutation status in Japanese lung cancer patients: genotyping analysis using LightCycler. Clin Cancer Res 11: 2924-2929, 2005.

21. Sasaki H, Shimizu S, Endo K, et al: EGFR and erbB2 mutation status in Japanese lung cancer patients. Int J Cancer 118: 180-184, 2006.
22. Ichinose $\mathrm{Y}$, Yano T, Yokoyama H, et al: Postrecurrent survival of patients with non-small-cell lung cancer undergoing a complete resection. J Thorac Cardiovasc Surg 108: 158-161, 1994.

23. Walsh GL, O'Connor M, Willis KM, et al: Is follow-up of lung cancer patients after resection medically indicated and cost-effective? Ann Thorac Surg 60: 1563-1572, 1995.

24. Ichinose Y, Kato H, Koike T, et al: Overall survival and local recurrence of 406 completely resected stage IIIa-N2 non-small cell lung cancer patients: questionnaire survey of the Japan Clinical Oncology Group to plan for clinical trials. Lung Cancer 34: 29-36, 2001

25. Mitsudomi T, Nishioka K, Maruyama R, et al: Kinetic analysis of recurrence and survival after potentially curative resection of nonsmall cell lung cancer. J Surg Oncol 63: 159-165, 1996.

26. Yano T, Hara N, Ichinose $Y$, et al: Local recurrence after complete resection for non-small-cell carcinoma of the lung. Significance of local control by radition treatment. J Thorac Cardiovasc Surg 107: 8-12, 1994.

27. Emami B, Graham MV, Deedy M, Shapiro S and Kucik N: Radiation therapy for intrathoracic recurrence of non-small cell lung cancer. Am J Clin Oncol 20: 46-50, 1997.

28. Sequist LV, Joshi VA, Jänne PA, et al: Response to treatment and survival of patients with non-small cell lung cancer undergoing somatic EGFR mutation testing. Oncologist 12: 90-98, 2007.

29. Yang CH, Yu CJ, Shih JY, et al: Specific EGFR mutations predict treatment outcome of stage IIIB/IV patients with chemotherapy-naive non-small-cell lung cancer receiving first-line gefitinib monotherapy. J Clin Oncol 26: 2745-2753, 2008.

30. Kosaka T, Yatabe Y, Endo H, et al: Analysis of epidermal growth factor receptor gene mutation in patients with non-small cell lung cancer and acquired resistance to gefitinib. Clin Cancer Res 12: 5764-5769, 2006

31. Lynch TJ, Bell DW, Sordella R, et al: Activating mutations in the epidermal growth factor receptor underlying responsiveness of non-small-cell lung cancer to gefitinib. N Engl J Med 350: 2129-2139, 2004. 